\title{
Bioelectric Impedance Analysis
}

National Cancer Institute

\section{Source}

National Cancer Institute. Bioelectric Impedance Analysis. NCI Thesaurus. Code C43545.

A method to assess body composition, i.e., the relative percentages of body weight comprised of fat tissue and lean body mass. It is based on the principle that the resistance to an applied electric current is inversely related to the amount of lean body mass within the body. Impedance is greatest in fat tissue, which contains only 10-20\% water, while lean body mass, which contains $70-75 \%$ water, allows the signal to pass much more easily. 